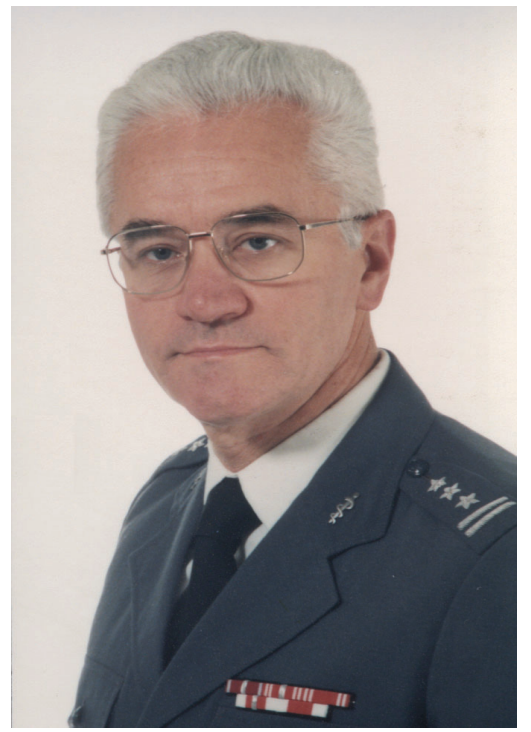

\title{
MY 45 YEARS OF WORK AS AN AVIATION LARYNGOLOGIST AT THE MILITARY INSTITUTE OF AVIATION MEDICINE
}

\author{
Zbigniew KACZOROWSKI
}

Source of support: Own sources

Author's address: Z. Kaczorowski, Warsaw, Poland, e-mail: zkacz@wiml.waw.pl

Abstract: The author, an aeronautical laryngologist who has been working at the Military Institute of Aeronautical Medicine for 45 years, presents a short history of this specialty in the period 1973-2000, in which he worked in the clinical and audiological-labyrinthological part of Military Institute of Aviation Medicine in Warsaw, acting as the Head of the Hearing and Balance Organ Clinic, which was equipped with a "silence chamber" and a unique at that time swivel chair with an electronic starter and a two-channel electronystagmograph, as well as an electronically controlled Toennies swivel chair for the examination of vestibular organs. The discussed research from this period in the field of laryngology concerned: pathophysiology of the balance organ, speech intelligibility under flight conditions and disorders of barofunction of ears and paranasal sinuses. Standards for pure tone audiometry and speech audiometry were among other things developed, which found practical application in routine commission tests. The author includes short biographical notes of many laryngologists working during this period and later at WIML and at the Aviation and Medical Commission.

Keywords: aviation laryngology, assessment methods in Polish aeronautical laryngology, profiles of Polish laryngologists working at Military Institute of Aviation Medicine in Warsaw for the last half a century 
The year 1928 can be considered the beginning of aviation medicine in Poland, when the Center for Aviation-Medical Research was established, and aviation laryngology became an important branch of aviation medicine. It is a field of medicine derived from otolaryngology. It is enriched with knowledge of aviation physiology and deals, among other things, with the impact of the aviation environment on the human organism. Its development could take place in an institution combining clinical activity in the field of otolaryngology, scientific activity in the field of aviation physiology and aero-medical certification. Therefore, the historical development of aviation laryngology could be achieved at the Military Institute of Aviation Medicine (MIAM) because these three fields were represented there from the very beginning.

The Center for Aviation-Medical Research had changed its name several times before and after the war, but it can be considered a precursor of the Military Institute of Aviation Medicine. I will skip the previous years of development of aviation health care while describing its history, and I will refer to the changes that had occurred immediately before I started my work at MIAM in 1973 as well as to the later changes and reorganizations concerning the Otolaryngologic Clinic until 2000 and the Hearing and Balance System Diagnostics Laboratory until 2018. Therefore, in this memoir, I am discussing the years 1973-2000 concerning the clinical and audiological-labyrinthological section, as my duties were connected with both of these structures during this period. I took over the position of the Head of the Hearing and Balance System Laboratory in 1999.

Referring to the establishment of the Military Institute of Aviation Medicine, it is necessary to analyze the processes that took place in aviation medicine in the second half of the fifties. Namely, in 1958, as a result of the merger of aviation certification and medicine with a temporary seat in Warsaw and Otwock, the Institute was established together with the Clinical Center and the Aviation and Medical Commission. It received a common name - Military Institute of Aviation Medicine, and in 1960 moved to a newly built complex of buildings at Krasińskiego 54 street in Warsaw.

In the first half of 1960s, MIAM developed an important scientific and experimental base. The Laboratory of Pathophysiology of the Hearing and Balance System, as it was then called, was equipped with a "silence chamber" and in 1965 with a swivel chair with an electronic starter and a two-channel electronystagmography stem, which was unique at that time. In 1975, a modern, second in Poland, electronically controlled Tönnies swivel chair for examination of vestibular organs was brought to the Laboratory.

Experimental works from this period, implemented for practical application in the field of laryngology, concerned: pathophysiology of the balance organ, speech intelligibility under flight conditions and disorders of barofunction of ears and paranasal sinuses. Standards for pure tone audiometry and speech audiometry were among other things developed, which found practical application in routine commission tests.

At that time the head of the laryngology unit was colonel Stanisław Pawłowski, M.D., Ph.D. and in 1966 It. col. Stanisław Czech, M.D., Ph.D. took over this position. The head of the laryngology unit from 1957 to 1973 was colonel Henryk Warnowski, M.D., Ph.D.

In 1972 a major reorganization of MIAM took place. The existing center of experimental pathophysiology was reorganized. The scientific laboratories were given the names of the Departments and in the Center of Aviation Pathophysiology clinical departments were transformed into clinics. Since 01.02.1973 the position of the head of the Laryngologic Clinic had been taken over by Associate professor Stanisław Chodynicki, M.D., dr hab. (doctor habilitatus), from the Otolaryngologic Clinic of the Medical Academy in Białystok, who employed me full time in the Clinic on 29.05.1973. Since 01.07.1973, the duties of the head of the clinic were transferred by Associate professor Chodynicki to Janusza Kubiczkowa, M.D., dr hab. (doctor habilitatus)., Associate Professor employed at MIAM in 1972, who later obtained the title of professor.

\section{MEMOIR OF PROFESSOR JANUSZA KUBICZKOWA}

Prof. Janusza Kubiczkowa, M.D., dr hab. (doctor habilitatus) was born in 1929 in Lviv. She graduated from the Medical Academy in Wrocław in 1952. In the years 1956-1972 she was employed at the Second Clinic of Laryngology, Physicians Improvement Institute in Bydgoszcz, as a Senior Lecturer. She obtained her M.D., Ph.D. degree in medical science in 1966 on the basis of the thesis entitled: "Vestibular lesions following a single and repeated thermal stimulus". In 1976 she obtained her post-doctoral degree (doctor habilitatus) in otolaryngology on the basis of her dissertation entitled: "Statokinesiometric test in the evaluation of balance". In 1983 she was conferred the title of professor of medical sciences. She is a 2 nd de- 
gree specialist in the field of otolaryngology and aviation medicine. From 1973 until she retired in 2000 she was employed as the head of the Otolaryngologic Clinic at MIAM. During this period, she also served as the chief laryngologist of the Air Force. She has published 125 scientific papers in Polish and foreign magazines. She is the co-authored five books'.

Scientific and didactic activity of prof. Janusza Kubiczkowa M.D. mainly concerned research on the physiopathology of the balance system, including, in connection with space flights, research on the role of the labyrinth in triggering motion sickness and its pharmacotherapy, the influence of Coriolis accelerations on the vestibular system, spatial orientation disorders, the influence of hypokinesia on the balance system, hearing organ and sense of taste, the influence of harmful factors on the balance system and the study of balance system functions using galvanic test. Pioneer studies of vestibulo-spinal reflexes using a posturograph, conducted by professor Janusza Kubiczkowa, as one of the first in Poland, with the simultaneous implementation of vestibular tests, allowed for an objective assessment of the balance system for clinical, certification and experimental needs. Posturography in peripheral damage of the balance system was also the subject of studies under the grant of the State Committee for Scientific Research (CSR).

Scientific and didactic activity of the Clinic under the direction of prof. Janusza Kubiczkowa included: pre-examination courses for the 1st and 2nd degree of otolaryngology major, postgraduate courses for civil and military medical doctors in otoneurology and laser surgery, lectures in laryngology centers, active participation in Congresses, national and international symposia, including: Meetings of the Otolaryngological Society, Scientific and Training Conferences, "Intercosmos" Symposia, Meetings of the Society of Posturography, Astronautical Meetings. Prof. Janusza Kubiczkowa, M.D., is a member of the International Society of Posturography and an honorary member of the Polish Society of Otolaryngologists - Head and Neck Surgeons. In 1984, the Clinic organized the 6th National Scientific and Training Conference for Laryngologists of the Polish Army at MIAM.

Prof. Janusza Kubiczkowa, M.D., dr hab. (doctor habilitatus) was the supervisor of 6 Ph.D. dissertations. Clinical interests included surgical treat-

1 "Aviation and Space Medicine", "Clinical Otoneurology" ed. 1, "Injuries in otolaryngology", "Specialist treatment of head injuries", "Clinical Otoneurology” ed. 2. ment of patients, among others, with head and neck cancers (total and partial laryngectomies), Crile's neck dissection, facial nerve decompression in otogenous paresis and parotid tumors, kofosurgery and laser surgery.

In 1980, the MIAM Otolaryngological Clinic was one of the first in Poland to use the $\mathrm{CO}_{2}$ laser and jet ventilation for the treatment of inflammatory and post-traumatic lesions, especially for the treatment of neoplastic lesions in the larynx, nose, oral cavity and laryngeal papillomatosis. Equipping the clinic with modern equipment: laryngeal microsurgery kit, $\mathrm{CO}_{2}$ laser, an ear surgery microscope, endoscopy kit, allowed to perform a wide range of otolaryngological surgeries.

When the Clinic was headed by prof. Janusza Kubiczkowa, the following military and civilian physicians were members of the team during various periods: at the Otolaryngologic Clinic Stanisław Czech, Zbigniew Baczyński, Zbigniew Kaczorowski, Marian Pawlik, Piotr Kapitan, Bohdan Dobrowolski, Wiesława Gerwatowska, Roman Stablewski, Jan Adam Jaskowski, Piotr Rozlau, and in the Laboratory of Pathophysiology of the Hearing and Balance System: Leszek Zaleski and Jan Nowicki (later professor), Jadwiga Wierciszewska, M.D. The volunteers specializing in otolaryngology, working at the Clinic, were: Wojciech Dębiński, Andrzej Zakrzewski, Andrzej Wolniak and Paweł Różycki. The otolaryngology specialty was acquired at that time by Mirosława Landowska, M.D., who was also a pilot at LOT Polish Airlines.

I owe my professional development to a large extent to professor Janusza Kubiczkowa and the 27-year period of our cooperation, for which I would like to thank her very sincerely in this memoir.

\section{MEMOIR OF PROFESSOR JAN NOWICKI}

The second professor who received this honorable title at MIAM is colonel prof. Jan Nowicki. He received his medical doctor's diploma at the Medical Academy in Gdańsk in 1950. A 2nd degree specialist in aviation medicine, otolaryngology and audiology. In the years 1959-1972 he was the Senior Lecturer in the Laboratory of Pathophysiology of the Hearing and Balance System, and in the years 1973-1994 he was the head of this laboratory, at that time known as the Hearing and Balance System Diagnostics Laboratory. Since 1984 he has been employed as the associate professor. He obtained his Ph.D. degree in 1967 on the basis of his dissertation: "Masking in speech audiometry through bone conduction", and in 1976 
he obtained the post-doctoral degree (doctor habilitatus) on the basis of the dissertation entitled: "The influence of aviation noise on binaural auditory integration in the light of a self-defined method of examination with distorted speech". In 1988 he was conferred the title of professor. He has published about 100 scientific papers (monographs, studies and articles). He is the co-author of the textbook "Basics of aviation medicine". He has carried out 18 scientific assessments. Supervisor of one Ph.D. dissertation. Scientific interests of colonel professor Jan Nowicki concerned audiology and labyrinthology, which resulted in the development of new methods of audiological and labyrinthological tests, the development of a method for testing binaural auditory integration, the determination of practical applicability of threshold tests and speech audiometry in audiological diagnostics, the development of individual and general principles of noise prevention in aviation. The author of this study actively cooperated with prof. Nowicki within the scope of these works. Colonel. prof. Jan Nowicki, M.D., officially retired in 1991 and continued his scientific work at the Institute until 2005 as a civil employee of MIAM, professor - scientific consultant of the Military Institute of Aviation Medicine. He died on 05.02.2014.

I gained a lot of experience in the field of scientific work during the period of 32 years of cooperation with professor Jan Nowicki. He was an advocate of promoting me to become doctor habilitatus. I will repeat the last sentence from my farewell to the professor during his funeral in February 2014: "We say goodbye to you, professor, and we promise you that you will always remain in our memory".

Returning to the issues related to the Otolaryngologic Clinic, it is worth mentioning the subsequent heads of the units, who additionally performed the function of the Deputy Head of the Clinic. In the following years these were: colonel Stanisław Czech, M.D., dr hab. (doctor habilitatus) (in the years 1973-1979), It. col. Zbigniew Baczyński, M.D., Ph.D. (in the years 1979-1985) and colonel Zbigniew Kaczorowski, M.D., Ph.D. (in the years 1985-1999).

\section{MEMOIR OF OTHER AVIATION LARYNGOLOGISTS}

Among the long-term employees of the MIAM Otolaryngologic Clinic, the following people should be mentioned:

\section{Colonel Leszek Zaleski, M.D., Ph.D.}

Obtained the medical doctor's diploma in 1939 and in the same year was appointed to professional military service, serving as a military physician. After moving to reserve in 1947, he specialized in the field of laryngology in Warsaw. In 1952, he was again called for the professional military service, initially as the head of the hospital laryngology unit and then the head of the laboratory of the Central Institute of Aviation and Medical Research. During this period, he was also the chief laryngologist of the Air Force. He was a specialist in otolaryngology and aviation medicine and in 1962 obtained the degree of the Doctor of medical science on the basis of his dissertation entitled: "The use of speech audiometry in aviation". Author of 20 scientific papers, mainly in the field of audiology and otoneurology. He moved to the reserve in 1973. He died in 1997.

\section{Colonel Stanisław Czech, M.D., dr hab.}

Received his medical doctor's diploma at the Medical Academy in Lublin in 1953. After two years of work in the Otolaryngological Clinic in Lublin, he was called for professional military service in the aviation unit in Świdwin. After acquiring the first degree specialty in laryngology, he was transferred to the Aviation Hospital in Otwock as a senior assistant, and in 1960 he was appointed the senior assistant at MIAM. He was the second degree specialist in laryngology and aviation medicine. In 1967, he was conferred the PhD degree after defending his dissertation entitled: "Modification of the research on the ability to balance the intra-auricular pressure in the low pressure chamber for the assessment and selection of candidates for pilot schools on the basis of own material". From 1973 to 1979, he was the head of unit and the Deputy Head of MIAM Otolaryngologic Clinic and later the head of the Laryngology Unit at the Main Military Aviation and Medical Commission (MAMC) In 1987, he was awarded the post-PhD degree (doctor habilitatus) on the basis of the dissertation entitled: "Value of impedance audiometry for clinical aviation medicine", under the scientific supervision of prof. Janusza Kubiczkowa. He published 35 scientific papers and was working in the field of aviation and space medicine, audiology and aviation-medical certification. He moved to the reserve in 1994 and died on 12.08.1996.

\section{Lt. col. Zbigniew Baczyński, M.D., Ph.D.}

Received his medical doctor's diploma at the Medical Academy in Warsaw in 1952. Recruited 
to the army, he served as a physician in the Air Force Communications Regiment in Nowy Dwór Mazowiecki and in the Artillery Regiment of the National Air Defense Forces in Warsaw. In 19691971, he was delegated to the Otolaryngologic Clinic at the IKP WAM, where he acquired the first degree specialty in laryngology. In 1972, after acquiring the second degree specialty in the field of laryngology and aviation medicine, he took up the position of the Senior Assistant and then of the Senior Lecturer at the Laryngologic Clinic at MIAM. In 1978, he defended his Ph.D. dissertation entitled: "Electronystagmography of vestibular functions in parasitic diseases of the digestive tract" under the supervision of prof. Janusza Kubiczkowa. In the same year he became the head of the Otolaryngologic Clinic. He published $8 \mathrm{sci}-$ entific papers. He moved to the reserve in 1985 and was appointed the Head of the Laryngological Unit of the hospital in Ciechanów. He retired in 1994. He has been dead for 2 years.

\section{Colonel Zbigniew Kaczorowski, M.D., Ph.D.}

Dear Reader, please forgive me a more casual and more detailed presentation of my own biography below.

I have been working at the Military Institute of Aviation Medicine for over 45 years. I was born in Radzyń Podlaski on 21.07.1941 in a twostore tenement family house with a direct view on a beautiful Baroque park and palace complex of the Potocki family. I don't know to what extent this influenced the fact that my wife Teresa is a gardener, Eng. and our older daughter Agnieszka is an art historian. I know, however, that I had an influence on my younger daughter Małgorzata, who partly followed in the footsteps of her father and family traditions and became a radiologist. Since 1945, I have been associated with Warsaw, specifically with Grochów in the area of Szembek Square. I received my first education at Primary School No. 54 at Kordeckiego Street, behind which there was a huge field of wasteland, covered with bomb craters from the war period with concrete shelters, where in 1964 the 2nd Central Clinical Hospital of the Military Medical Academy and the surrounding housing estates were built.. Then I graduated, in the years 1960-1966, I studied at the 3rd Course of the Faculty of Medicine of the Military Medical Academy in Łódź, which I recall with fondness. I received my medical doctor's diploma in 1966. After 2-year post-graduate internship at IKP WAM (renamed from 2 CSK WAM) and 3 years of work as a senior physician of the Sick Ward, the Deputy Head of Health Service of the 3rd
Division of the Air Defense Forces of the Country I received the 1st degree of specialization in the field of otolaryngology.

After acquiring the specialty, on 29.05.1973, I was transferred to the position of the Senior Lecturer, approved in 1976, to the Otolaryngologic Clinic of the Military Institute of Aviation Medicine. I completed my qualifications by acquiring two levels of specialty in aviation medicine and the second degree specialty in otolaryngology. I obtained the degree of the doctor of medical science in 1980 on the basis of my dissertation entitled: "The lesions of the vestibular organ and vegetative system following the cumulative effect of Coriolis accelerations", under the kind patronage of professor Janusza Kubiczkowa. From 1985 to 1999 I was the head of the unit and the Deputy Head of the Otolaryngologic Clinic at MIAM. In the years 1997-1999, I was employed as the Head of the Department. On 26.04.1999, being a Colonel, I retired and took the position of head of the MIAM Hearing and Balance System Diagnostics Laboratory, which I have been holding until now.

For my scientific work at MIAM, I have received the following awards: Distinction - 1981 and annual MIAM awards: 1st place in 1981, 3rd place in 1983, 1984 and 1989.

I attended foreign training courses and scientific symposia.

I actively participated in many national and international scientific conferences in the field of otolaryngology, otoneurology, audiology and aviation medicine. In the years 1991-1999 and 2004-2007, I was a member of the Scientific Council of the Military Institute of Aviation Medicine.

I have published 44 scientific and research papers. My scientific interests include: research on labyrinth physiopathology, aviation and space medicine with particular emphasis on spatial disorientation and air sickness, objective, digital evaluation of the balance system, clinical audiology and laryngology.

Since 1994 I have been authorized to issue medical certificates as part of preventive tests in occupational medicine and since 2000 to issue medical certificates for drivers (including motor vehicle drivers), as well as to examine people possessing gun or applying for a shot-gun license. In the years 20012005 I was a member of the Medical Council of the Military Medical Chamber (MMC) and for the past four 4-year long tenures I have been elected a judge of the MMC Medical Court. I have been an expert in otolaryngology at the District Court and Regional Courts in Warsaw for three years. During my professional work, two events occurred that I view very critically. The first one was the liquidation of the Military Medical Academy in its previous form, as it ex- 
cellently trained the medical personnel within the scope of the specific tasks faced by military medical doctors. The second event, of a nationwide scale, was the introduction in the last two decades of commercialization of health care in its existing form, which resulted in a significant deterioration of the patient-physician relationship, as well as the relations between the physicians. It has also extremely hindered organizational, scientific and therapeutic work of the heads of health care institutions at various levels, concentrating it on the struggle for the survival of institutions. In my opinion, health care has also become very expensive through excessive computerization and the development of unnecessary administrative structures.

\section{Colonel Roman Stablewski, M.D., Ph.D.}

Received his medical doctor's diploma at the Military Medical Academy in Łódź in 1975. After completing a postgraduate internship at MIAM in years 1976-1979, he was an aviation physician of the 26th Communication Air Force Squadron in Warsaw. In 1979, he was delegated to MIAM. Since 1981 he had been employed as an assistant at the MIAM Otolaryngologic Clinic. Since 1999 he had been the Clinic Research Associate, as well as a second degree specialist in otolaryngology, aviation medicine and audiology. In 1999, he obtained the degree of the Doctor of medical science on the basis of his dissertation entitled: "Research on the influence of simulated high-altitude hypoxia and changes in atmospheric pressure on the balance control and barofunction of the hearing system and sinuses" prepared under the supervision of prof. Janusza Kubiczkowa. He has published 15 scientific papers. The subject of scientific interest is clinical and experimental pathophysiology of the balance system and hearing organ under changing conditions of barometric pressure and hypoxia. Clinical interests include issues related to diagnostics (endoscopy) and treatments to improve the barofunction of ears and sinuses, laser surgery and problems related to acoustic injury. From 2000 to 28.10.2014, he was the Head of the Clinic. Since 28.10.2014, the Head of the Clinic became prof. Andrzej Wojdas, M.D., former longtime employee of the Otolaryngologic Clinic of the Military Medical Institute at Szaserów Street.

\section{Colonel Marian Pawlik, M.D., Ph.D.}

Received his medical doctor's diploma at the Military Medical Academy in 1965. After a medical internship he had been working as a senior regiment physician in Dęblin until 1978. In 1973, he was employed as a senior assistant of the MIAM
Otolaryngologic Clinic and in the years 1982-1994 he had been working as the Senior Lecturer. He is the second degree specialist in otolaryngology, aviation medicine and phoniatrics. In 1986, he obtained the degree of the Doctor of medical science on the basis of his dissertation entitled: "Study of the hearing ability of pilots in circadian rhythm" under the supervision of prof. J. Nowicki. After an internship abroad in Paris in 1995, he was certified as an aviation medicine specialist in France. From 1995 to 1999, he was a deputy chairman of the Laryngology Unit at the Main Military Aviation and Medical Commission (MAMC). After his retirement in 1999, he was the chairman of the Aviation and Medical Commission and subsequently he became the chairman of the MIAM Center for Aviation Medicine for Civil Aviation Personnel. He passed away in 2015.

\section{Lt. col. Piotr Kapitan, M.D.}

Received his medical doctor's diploma at the Military Medical Academy in 1965. After a medical internship he had been working as a senior aviation regiment physician in Mińsk Mazowiecki until 1973. In 1973 he was employed as the Senior Lecturer, the head of the Documentation and Medical Publishing Department at WIML, and subsequently, in the years 1989-94, he was a senior assistant at the MIAM Otolaryngologic Clinic. He is the first degree specialist in otolaryngology and the second degree specialist in aviation medicine. In the years 1994-1999, he was a senior specialist of the Central Military Medical Commission. He retired in 2000 and now serves as a member of the Aviation and Medical Commission.

\section{Colonel Bohdan Dobrowolski, M.D., Ph.D.}

Received his medical doctor's diploma at the Medical Academy in Warsaw in 1966 and was appointed to serve periodically as a physician in the Engineer Military Regiment in Dęblin. After his transition to the professional military service, he was employed in the military institute of the Medical Academy in Warsaw. In the years 1974-1981, he was employed as a senior assistant in the MIAM Otolaryngologic Clinic. In 1979, he obtained the degree of the Doctor of medical science on the basis of the dissertation entitled: "Influence of normobaric hyperoxia on the mucous membrane of trachea" conducted under the supervision of prof. Janusza Kubiczkowa. At the beginning of the 1980s, he left for the The Ministry of Internal Affairs and Administration. Hospital and then for ambulatory work in the Specialist Clinic. He has been dead for several years. 


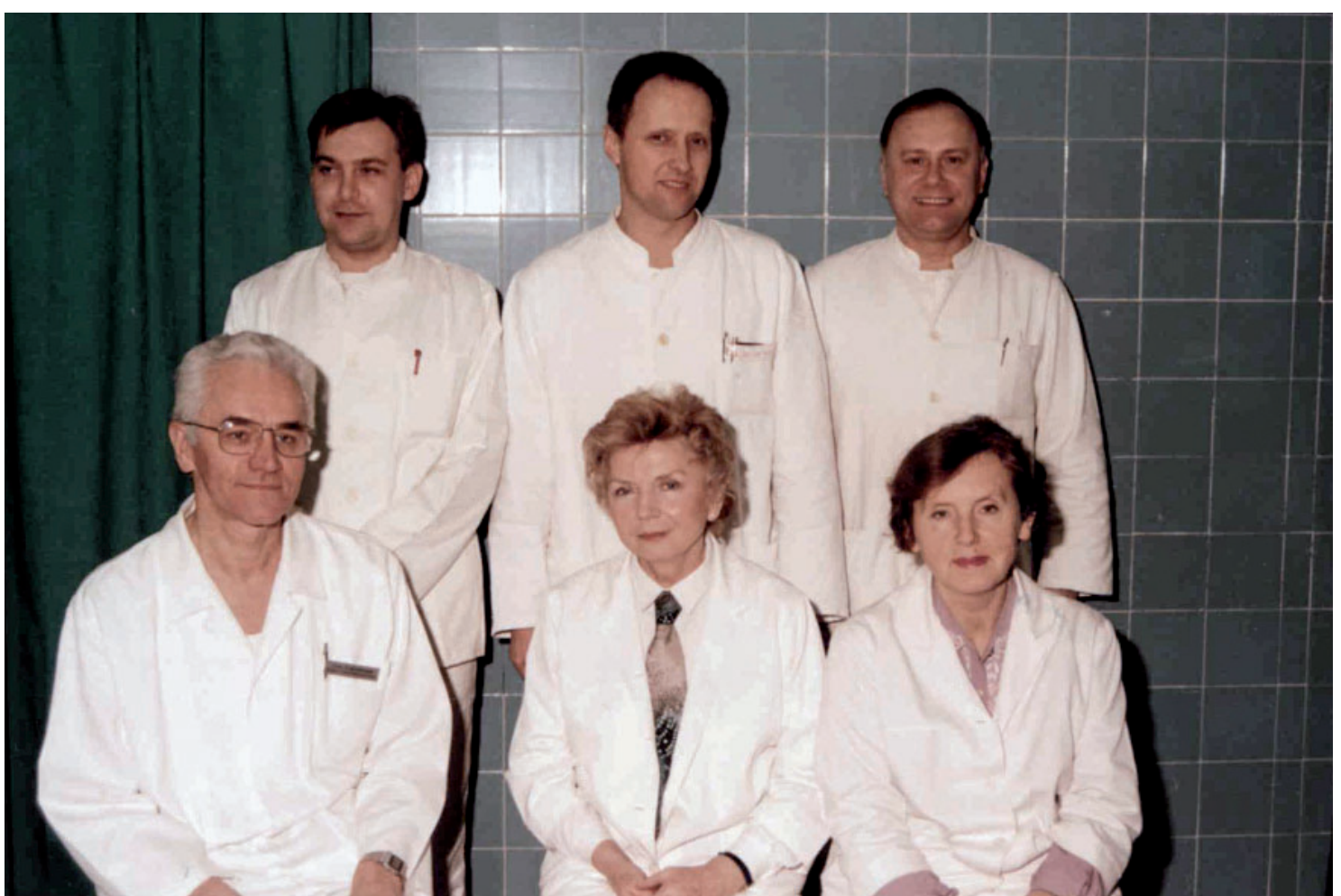

Fig. 1. Medical personnel of the MIAM Otolaryngologic Clinic in 1996. (from the right, sitting: Wiesława Gerwatowska, M.D., Ph.D., prof. Janusza Kubiczkowa, M.D., colonel Zbigniew Kaczorowski, M.D., Ph.D.; from the right, standing: It. col. Adam Jaskowski, M.D., It. col. Roman Stablewski, M.D., Captain Piotr Rozlau, M.D.).

\section{Colonel Jan Adam Jaskowski, M.D.}

Received his medical doctor's diploma at the Military Medical Academy in 1977 and was sent to work as a physician in the Helicopter Aviation Regiment in Inowrocław. In 1981, he was employed in the MIAM Otolaryngologic Clinic as an assistant and in 1989 as the Senior Lecturer. He is the author or co-author of 22 scientific papers. He left the clinic in 1996 to become a senior specialist, head of the Central Military Medical Commission (CMMC) Laryngological Department. In 1998, he became the Deputy Chairman and in 2002 the CMMC of the Air Force. In 2012, he became the Deputy Head of the Research Center for the Aero-Medical Certification and since June 2018 - the Head of the Center.

\section{Wiesława Gerwatowska, M.D., Ph.D.}

Received her medical doctor's diploma at the Medical Academy in Łódź in 1972. After a postgraduate internship in the years1973-1984, she was working as a senior assistant at the Otolaryngologic Clinic of Military Medical Academy in Łódź. In 1984, she was employed as a senior assistant and then the Senior Lecturer at the MIAM Otolaryngologic Clinic. She is the second degree specialist in otolaryngology. In 1981, she received her Ph.D. degree on the basis of her dissertation entitled: "Behavior of certain immune responses in the course of malignant neoplasms of the lar$y n x$, lip and jaw" under the supervision of prof. $K$. Najwer. Since 1991, she has been working as the senior assistant of the Department of Laryngology of the MIAM Polyclinic.

\section{Major Piotr Rozlau, M.D.}

Received his medical doctor's diploma at the Military Medical Academy in 1990. After a postgraduate internship, he had been working as a senior missile defense regiment physician in Mrzeżyn until 1995. In 1995, he was employed as an assistant in the MIAM Otolaryngologic Clinic. He is the first degree specialist in otolaryngology, aviation medicine and audiology. Since 2001, he has been employed as the Senior Lecturer in the Department of Laryngology of the Aviation and Medical Commission. He also works as an examiner at the MIAM Center for Aviation Medicine.

\section{STRUCTURAL AND STAFF CHANGES IN THE 1990S}

At the end of the 1990s, after the completion of the first stage of the three-year renovation of the hospital premises, staff and structural changes took place. In the Otolaryngologic Clinic, apart 
from It. col. Roman Stablewski, M.D., Ph.D. serving as the head of the Clinic, the following were employed as senior assistants: captain Michał Michalik, M.D. and captain Dariusz Kalinowski, M.D., the second degree specialists in otolaryngology and aviation medicine. Since 2001, second lieutenant Marcin Broda, M.D. specializing according to the new program in otolaryngology, delegated from the alternate position at the Air Force and Air Defence was employed at the clinic, as well as captain Krzysztof Cecherz, M.D..

Zbigniew Kaczorowski, M.D., Ph.D. took over the position of the head of the Hearing and Balance System Diagnostics Laboratory in 1999, Wiesława Gerwatowska, M.D., Ph.D. became the senior assistant in the Department of Laryngology of the Polyclinic and captain Piotr Rozlau, M.D. took over the position of the senior assistant in the Department of Laryngology in the Aviation and Medical Commission.

In addition to the organizational structure of the Otolaryngologic Clinic, there were also the following laryngologists: colonel Marian Pawlik, M.D., Ph.D., It. col. Adam Jaskowski, M.D. and It. col. Wojciech Dębiński, M.D. taking up executive positions within the Main Military Aviation and Medical Commission (MAMC), as well as It. col. Piotr Kapitan, M.D. - an employee of MAMC, It. col. Wiesław Kluch, M.D. took over the position of the head of the Spatial Orientation Laboratory for several years.

The function of the ward nurse, initially of the combined Laryngological and Ophthalmology Departments and then from 1972 the Laryngological Clinic was held by: Romana Adamiak in years 1960-1975, Aleksandra Winiarska in years 1975-1991, Bożena Jedynak in the 1990s and subsequently Barbara Bomblicka and Małgorzata Rojek-Romanowska. Currently, since 01.06.2015, the function of the ward nurse is held by Anna Szczepańska.

In the years 1953-1960 in Otwock and 19601991 at MIAM, the position of the Head of the Operating Block was held by nurse Apolonia Paszkowska and subsequently, for about fifteen years, by Weronika Wojewódzka, who died in June this year. Then, for several years, the function was taken over by Danuta Stachowska and from 2015 by Żaneta Szychowska. The function of the nurse of the operating block was also held by Elżbieta Sokołowska and Anna Kościńska in different periods of time.

The function of a senior technician at the Laboratory of Pathophysiology of Hearing and, since 1973, the Laboratory of Pathophysiology of the Hearing and Balance System was performed by
Danuta Cholewka until 1974, then, from 1975 to May 2016, by Anna Krziskowska, who showed an extraordinary commitment during the 41 years of work at this position, for which, as a long-time colleague, I would like to thank her very warmly in this memoir. After Anna Krziskowska's departure, senior nurse Bożena Bomblis, has taken over the function and has been working until now.

Scientific interests of the team, concerning aviation medicine in the discussed years, included the following issues: impact of working conditions of flying and technical personnel on the hearing and balance organ, prevention and treatment of occupational perceptual hearing damage, determination of hazardous zones at workstations of particular airplane types, determination of aviation noise characteristics for different types of airplanes and technical equipment, barofunctional disorders of ears and sinuses.

Apart from the preventive and surgical treatment, discussed during the description of prof. Janusza Kubiczkowa's activity, the following courses were organized in the clinic: training courses in aviation laryngology; pre-examination courses for the first and second degree specialties in otolaryngology; postgraduate courses in otoneurology and laser surgery; postgraduate courses for physicians applying for preventive tests authorizations; for physicians applying for authorization to examine candidates for drivers and for physicians applying for authorization to examine people possessing gun or applying for a shot-gun license.

The clinic's medical team actively participated in national otolaryngologist conventions, scientific and training conferences of military laryngologists, NATO / HFM / RTO symposia.

Equipping the clinic in the 1990s with a functional nose and sinus endoscopy kit created new possibilities of diagnostics and treatment of upper respiratory tract lesions leading to barofunctional disorders.

In the years 1970-2008, 6 otolaryngologists were awarded the academic Ph.D. degree, 3 post-doctoral degrees and 2 were conferred a title of Professor at MIAM. The second degree specialty in otolaryngology was obtained by 8 physicians and the first degree specialty- by 5 physicians, 2 physicians obtained the specialty in audiology and 1 in phoniatrics. The full-time physicians had a specialty in aviation medicine.

At the end of the first decade and at the beginning of the second one, after the year 2000, they following physicians left the Clinic: Michał Michalik, Dariusz Kalinowski, Marcin Broda and Krzysztof Cecherz and the physicians employed 
in their place after 2010 were: Katarzyna KacperekWalewska, Elżbieta Zgnilec, Rafał Chmielewski and Paulina Zielińska. The function of the head of the Clinic was still held until 28.10.2014 by colonel Roman Stablewski, M.D., Ph.D. Since 28.10.2014, the position of the Head of the MIAM Otolaryngologic Clinic was taken over by colonel Andrzej Wojdas, M.D., dr hab. (doctor habilitatus), professor of MIAM.

In the Hearing and Balance System Diagnostics Laboratory, the following tasks have been and are currently being carried out:

1. Performing audiological and electronystagmographic tests for the purposes of aviation and medical certification and the clinic's needs.

2. Conducting scientific research in the field of aviation and clinical laryngology.

3. Implementation of preventive tasks counteracting the impact of harmful working environment conditions on the pilot's organism.

Since 1968, otoneurological diagnostics of patients with dizziness has already been practiced in the Laboratory. It was initiated by prof. Jan Nowicki, who simultaneously with prof. Zbigniew Bochenek, performed the first in Poland labyrinthological tests with the use of Toennies electronic equipment. In 1973, I joined these works and, under the scientific direction of prof. Kubiczkowa and prof. Nowicki, we developed our own methodology of tests, consistent with the generally binding world standards.

From the historical point of view, the laboratory has always had a unique equipment, especially for otoneurological tests, due to the need to perform balance system tests in aviation personnel and their importance for flight safety. Since 1965, the laboratory has had the following equipment to examine the balance system:

- 1965 - a swivel chair with an electronic starter and a two-channel electronystagmography stem;

- 1973 - a posturography machine - plate with a stimulator and printer (produced according to the design of MIAM engineers);

- 1975 - an ENG device with Toennies electronic swivel chair;

- 1980 - a device based on TV Libra Unitra WZT for the study of visual tests according to own methodology and design (a computer program for triggering visual stimuli for the visual and photic driving tests andoptokinetic tests using a black-and-white checkerboard);

- 1990 - a Jaeger electrostagmograph with swivel chair + TENA computer program with thermostat for calorific tests by Atmos;
- 1995 - a Jaeger-Toennies posturography machine - dynamic system with TOBIOS program and T-POST + biofeedback;

- 1998 - a VNG MK III Ulmer Videonystagmograph with RONEST swivel chair and Enthermo calorimeter;

- 2009 - an ENG / VNG System 2000 device by Micromedical Technologies, Inc. with automatic test interpretation with a swivel chair and Aqua Star calorimeter. Last year, the Aqua Star calorimeter was replaced by Varioterm Plus made by Atmos. In the near future we are also planning to purchase a new ENG/VNG device;

- Since 1960, the Audiometric Laboratory has been using the audiometers of Polish production. The first high-class clinical audiometer produced by Peters AP- 6 was brought to the Laboratory in 1974. Then, in intervals of about 10 years, the audiometers were replaced with the best ones on the market. Since 2014, we have been using the Interacoustic AC-4 clinical audiometer and since 2006 the Zodiak $901 \mathrm{im}$ pedance audiometer.

Since 1999, the Laboratory has been managed by colonel Zbigniew Kaczorowski, retired, M.D., Ph.D. After the departure of senior technician Anna Krziskowska, since May 2016, the senior nurse Bożena Bomblis, M.Sc., who is very involved in the tasks facing the Laboratory, has been employed.

In connection with the planned transfer of the Laboratory to new premises, next to the Otolaryngologic Clinic, a number of investments in medical equipment was made or planned, partially replacing the already existing equipment, as well as in new equipment increasing the diagnostic capabilities of the Laboratory. This year a new audiometric cabin was purchased. The impedance audiometer is currently being replaced by the Otometrics Madsen Zodiak impedance audiometer. We have also been fitted with otoemission and auditory evoked potential testing instruments (ABR) by Otometrics. Thanks to these devices we are expanding the methodology of hearing organ examination and diagnostic capabilities of the peripheral and central parts of the vestibular system. Excellent diagnostic equipment also gives us the possibility to provide services for hospitalized and ambulatory patients under the contracts signed with the National Health Fund and to conduct the WSOSP qualification tests every 6 months. A very important task of the Laboratory is also performance of occasional audiological and labyrinthological tests of the flying personnel. The laboratory is an integral part of the Otolaryngologic Clinic and is subordinate to the Head of the Clinic. 
At this point, at the end of my memoir, I wish the new Head of the MIAM Otolaryngologic Clinic, professor Andrzej Wojdas and my long-time colleague and sincere friend - the Deputy Head of the Clinic, Roman Stablewski, M.D., Ph.D., good luck in their positions. I also wish you to further develop the Clinic in cooperation with the Clinic Team, relying on new diagnostic possibilities and new operating techniques, for the benefit of aviation personnel and other patients treated at the Clinic. I am glad that it is you who will create the further history of Otolaryngology, Audiology and Aviation Otoneurology at the Military Institute of Aviation Medicine.

\section{AUTHORS' DECLARATION:}

Study Design: Zbigniew Kaczorowski; Data Collection: Zbigniew Kaczorowski; Manuscript Preparation: Zbigniew Kaczorowski. The Author declares that there is no conflict of interest.

Cite this article as: Kaczorowski Z. My 45 Years of Work as an Aviation Laryngologist at The Military Institute of Aviation Medicine. Pol J Aviat Med Bioeng Psychol 2017; 23(3-4): 53-62. DOI: 10.13174/pjambp.20.12.2018.09 